\title{
Safety and Efficacy of Recombinant Human Interleukin 10 in Chronic Active Crohn's Disease
}

\author{
STEFAN SCHREIBER, $*$ RICHARD N. FEDORAK, ${ }^{\dagger}$ OLE HAAGEN NIELSEN,§ GARY WILD, \\ C. NOEL WILLIAMS, $₫$ SUSANNA NIKOLAUS,* MERON JACYNA,\# BRET A. LASHNER,** \\ ALFRED GANGL, ${ }^{\ddagger}$ PAUL RUTGEERTS, $\$ \S$ KIM ISAACS, \|\| SANDER J. H. VAN DEVENTER, $\uparrow \uparrow$ \\ JACOB C. KONINGSBERGER, \#\# MARIELLE COHARD,*** ALESANDRE LEBEAUT,*** \\ and STEPHEN B. HANAUER, ${ }^{\dagger \dagger}$ FOR THE CROHN'S DISEASE IL-10 COOPERATIVE STUDY GROUP \\ *Charité University Hospital, Fourth Medical Department, Humboldt University, Berlin and Christian-Albrechts-University, First Department of \\ Medicine, Kiel, Germany; ${ }^{*}$ University of Alberta, Edmonton, Alberta, Canada; §Department of Gastroenterology, Copenhagen University \\ Hospital, Glostrup, Denmark; "McGill University, Montreal, Quebec, Canada; IDalhousie University, Halifax, Canada; \#Northwick Park \& St. \\ Marks NHS Trust, Harrow, England; **Cleveland Clinic Foundation, Cleveland, Ohio; ^¥University Clinic for Internal Medicine IV, Vienna, \\ Austria; §§Department of Gastroenterology, Leuwen University Hospital, Leuwen, Belgium; IllUniversity of North Carolina, Chapel Hill, North \\ Carolina; "ITAcademic Medish Center, University of Amsterdam, Amsterdam, The Netherlands; \#\#niversity Hospital, Utrecht, The Netherlands;

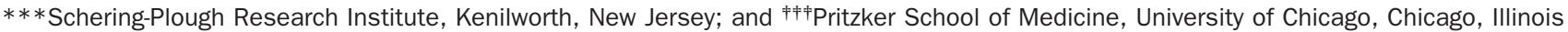

\section{See editorial on page 1781}

Background \& Aims: Interleukin (IL)-10 is a cytokine with potent anti-inflammatory properties. We investigated the safety and efficacy of different doses of human recombinant (rhu)IL-10 in patients with Crohn's disease (CD). Methods: A prospective, multicenter, double-blind, placebo-controlled study was conducted in 329 therapy-refractory patients with CD. Clinical improvement was defined by a reduction of the Crohn's Disease Activity Index (CDAI) by 100 points or more and clinical remission by a decrease of the CDAl to $<150$ points. At selected centers, patients underwent ileocolonoscopies and activation of the nuclear factor- $\kappa B$ (NF-kB) system was assessed in biopsy specimens. Results: Subcutaneous treatment with rhulL-10 over 28 days induced a fully reversible, dose-dependent decrease in hemoglobin and thrombocyte counts but no clinically significant side effects. No differences in the induction of remission were observed between rhulL-10 groups (1 $\mu \mathrm{g}, 18 \%$ [9.6-29.2]; $4 \mu \mathrm{g}, 20 \%$ [11.3-32.2]; $8 \mu \mathrm{g}, 20 \%$ [11.1-31.8]; $20 \mu \mathrm{g}, 28 \%$ [18-40.7]; and placebo, 18\% [9.6-29.6]). Clinical improvement was observed in $46 \%(33.7-59)$ in the $8-\mu \mathrm{g} / \mathrm{kg}$ rhulL-10 group in comparison with $27 \%$ (17-39.6) in patients taking placebo. Responders to rhulL-10 showed inhibition of NF-kB p65 activation in contrast to nonresponders. Conclusions: Up to $8 \mu \mathrm{g} / \mathrm{kg}$ of rhulL-10 was well tolerated. A tendency toward clinical improvement but not remission was observed in the $8-\mu \mathrm{g} / \mathrm{kg}$ dose group. Further studies should delineate which subgroups of patients with CD benefit from rhulL-10 therapy.
Athough the cause of inflammatory bowel disease A remains to be elucidated, considerable progress has been made in the characterization of key elements of the pathophysiology of chronic intestinal inflammation. The enhanced secretion of proinflammatory cytokines appears to be an important factor in the initiation and perpetuation of intestinal inflammation. ${ }^{1-4,5}$ Anti-inflammatory treatment strategies with steroids or other immunosuppressive drugs, which have largely been developed empirically, ${ }^{6,7}$ remain unsatisfactory and do not induce endoscopic healing in the short term. ${ }^{8}$

Interleukin (IL)-10, which was identified in 1989 as cytokine synthesis-inhibitory factor, ${ }^{11}$ profoundly inhibits effector functions of activated macrophages and monocytes in vitro. ${ }^{9}$ IL-10 down-regulates the production of proinflammatory cytokines, interferon $\gamma$, and, to a lesser extent, IL-2 production by type 1 T-helper cells. ${ }^{10}$ In various in vitro and in vivo models, IL-10 shows a strong anti-inflammatory effect. ${ }^{11-14}$ This effect may be mediated by inhibition of the activation of nuclear factor- $\mathrm{KB}(\mathrm{NF}-\mathrm{\kappa B}),{ }^{15,16}$ a transcription factor that initiates or augments the expression of many proinflammatory mediators. ${ }^{17}$ Glucocorticoids exert some of their anti-inflammatory actions similarly to IL-10 by inhibition of the activation of NF- $\mathrm{BB} .{ }^{18,19}$

Abbreviations used in this paper: CDAl, Crohn's Disease Activity Index; CDEIS, Crohn's Disease Endoscopic Index of Severity; IBDQ, inflammatory bowel disease questionnaire; rhulL-10, recombinant human interleukin 10; NF-кB, nuclear factor-кB; QOL, quality of life.

(C) $\mathbf{2 0 0 0}$ by the American Gastroenterological Association 0016-5085/00/\$10.00 doi:10.1053/gast.2000.20196 
IL-10 is involved in the maintenance of the normal noninflammatory state of the intestine. ${ }^{20}$ In vitro, IL-10 inhibits the proinflammatory activities of mononuclear cells that have been isolated from the intestinal lamina propria of patients with inflammatory bowel disease. ${ }^{12}$ Previous studies suggested a therapeutic activity of IL-10 in mild-to-moderate, untreated Crohn's disease $(\mathrm{CD})^{21}$ as well as in chronic, active, steroid-refractory disease. ${ }^{22}$ Other anti-inflammatory approaches, which include the use of monoclonal antibodies against the proinflammatory cytokine tumor necrosis factor $\alpha$, one of the main activators of the NF- $\mathrm{KB}$ system, have been effective in inducing remission in $30 \%-50 \%$ of patients with therapy-refractory $\mathrm{CD}{ }^{23}$

This study was designed to evaluate the safety and efficacy of a 28-day treatment period with subcutaneous recombinant human (rhu)IL-10 in patients with chronic, active, steroid-refractory CD. In addition to the Crohn's Disease Activity Index (CDAI) ${ }^{24}$ and quality of life (QOL), the Crohn's Disease Endoscopic Index of Severity $(\mathrm{CDEIS})^{8}$ and the activation status of the NF- $\mathrm{\kappa B} /$ inhibitor $\kappa \mathrm{B}(\mathrm{I} \kappa \mathrm{B})$ system in the intestinal mucosa was assessed in a subpopulation of patients.

\section{Patients and Methods}

\section{Patients}

Eligible patients were adults with chronic active CD. Chronic active $\mathrm{CD}$ was defined by (1) a previous diagnosis of $\mathrm{CD}$ as documented by clinical, endoscopic, or histologic findings; (2) inflammation involving the colon, ileum, and colon or endoscopically evaluable disease of the ileum only, with or without external fistulas; and (3) a CDAI score during the week before inclusion into the study between 200 and 400 points despite treatment with systemic glucocorticoids for at least 3 months, with or without azathioprine/6-mercaptopurine for at least 6 months before study drug administration. If patients received azathioprine/6-mercaptopurine, the dose had to be constant for at least 3 months. The dose of prednisone was required to be stable at $10-40 \mathrm{mg} /$ day (or equivalent) for at least 2 weeks before screening. Concomitant anti-inflammatory medications (immunomodulators, glucocorticoids) were kept constant throughout the treatment phase. Retaining glucocorticoids at a stable level was intended to allow a clearer evaluation of the potential anti-inflammatory effects of rhuIL-10 in the study setting, although it would be desirable for patient management to ultimately reach a state of steroidfree remission. Patients undergoing aminosalicylate or metronidazole therapy were included in the study if a constant regimen was followed both during the 4 weeks before study drug administration and throughout the study. Treatment was considered to have failed in subjects with a change in concomitant medication for the management of $\mathrm{CD}$. Antibiotics for the treatment of $\mathrm{CD}$ other than metronidazole were not per- mitted. Antispasmodic agents were permitted if intake of this medication was kept constant for at least 2 weeks before study drug administration and throughout the study. Although acetaminophen and paracetamol were allowed, aspirin and nonsteroidal anti-inflammatory drugs were not permitted. Codeine and other opiates, parenteral nutrition, or defined formula diets were not permitted in the study. Inhaled steroids and steroid ointments were permitted, as was the use of loperamide for the symptomatic control of diarrhea.

The CDAI was used to assess disease activity. ${ }^{24}$ Endoscopic activity was graded by using the CDEIS, which represents an additive score calculated from the extent (percent of surface inflamed) and severity (type of lesion) of involvement in different anatomic parts of the colon and in the ileum. Extra points are added for inflammatory stenoses. ${ }^{8}$

Patients matching the following criteria were excluded: colostomy or ileostomy, intestinal resection resulting in clinically relevant short-bowel syndrome, isolated small bowel involvement that was not evaluable by endoscopy, presence of fixed strictures with clinical signs of current or recent bowel obstruction, a foreseeable need for a surgical procedure, detection of pathogens or Clostridium diffcile toxin in the stool, previous therapy with rhuIL-10, or previous experimental immunomodulatory drug therapy within 90 days of study entry. The use of any other class of experimental drug within 30 days of study entry was prohibited. Further exclusion criteria were a clinically significant abnormal laboratory test result, a significantly abnormal chest radiogram or electrocardiogram, active infection, a positive serum test for antibodies against hepatitis C virus, detection of hepatitis B surface antigen or human immunodeficiency virus, alcohol or drug abuse within the previous 5 years, a history of cancer, or a body weight $>100 \mathrm{~kg}$. Women of childbearing age were required to have a negative pregnancy test result within 24 hours of initiating study drug and were required to practice adequate birth control for the duration of the study. Breast-feeding women were excluded from the study.

\section{Protocol}

The study was planned to be conducted in 37-42 active centers, with $10-25$ subjects per center and a total enrollment of at least 300 evaluable subjects. The sample size was calculated to detect a $30 \%$ difference in response rates (primary parameter, achievement of clinical remission as defined later) between any of the rhuIL-10 dose groups and the placebo group with a $90 \%$ power and an $\alpha$ error of $\leq 5 \%$ (2-sided test).

Patients were enrolled between February 1996 and October 1997 at 43 centers in Canada, Europe, and the United States. The protocol was approved by the institutional review boards and/or ethics committees of all participating sites before local initiation of the study. All patients gave written, informed consent at least 24 hours before enrollment in the trial.

A multistage, multicenter, prospective, randomized, double-blind, placebo-controlled study was conducted to evaluate the safety, tolerability, and efficacy of 4 doses of rhuIL-10 (1, 
4, 8 , and $20 \mu \mathrm{g} / \mathrm{kg}$ body wt) in comparison with placebo. rhuIL-10 (Tenovil) was manufactured and provided by Schering-Plough Research Institute (Kenilworth, NJ). After a 2-week screening period, in which the CDAI was obtained prospectively, patients were randomized to receive subcutaneous treatment with rhuIL-10 or placebo daily for 28 consecutive days and were followed up for an additional 4 weeks after treatment. Central randomization was used, and patients were stratified according to steroid dose ( $\leq 20 \mathrm{mg} /$ day prednisone [or equivalent] vs. $>20 \mathrm{mg} /$ day) and the use of immunosuppressive agents. At selected centers, (ileo)colonoscopies were performed immediately before and within 48 hours after conclusion of treatment. The CDEIS $^{8}$ was locally assessed before and after treatment. Colonic biopsy specimens were obtained at selected centers to study the activation of transcription factors.

During the study, 2 previously planned interim evaluations were performed by an independent data monitoring committee. After approximately 50 patients had completed treatment, safety was evaluated in a blinded fashion, and after treatment of 151 patients, an unblinded analysis (within the data monitoring committee) of the effect of rhuIL-10 on CDAI was conducted. None of the interim analyses had an effect on the study conduct. The study was conducted in compliance with Good Clinical Practice and international clinical research ethics standards.

\section{Clinical Evaluations}

The primary endpoint for the efficacy evaluation was clinical remission as defined by a CDAI score of $<150$ points accompanied by a decrease in the score of at least 100 points from baseline. Secondary endpoints were (1) clinical improvement (as defined by a decrease of the baseline CDAI of at least 100 points); (2) endoscopic improvement (as defined by reduction in the CDEIS); (3) effect of treatment with rhuIL-10 on health-related QOL (Inflammatory Bowel Disease Questionnaire [IBDQ] and short form [SF] 36 health survey); and (4) effect of treatment with rhuIL-10 on proinflammatory transcription factor activity at the end of the treatment period.

Safety and tolerance of study drug treatment were evaluated based on assessments of clinical adverse events and laboratory findings occurring throughout the study. Patients kept daily diaries and were examined at regular intervals during the treatment phase (days 8, 15, 29) and follow-up (weeks 2 and 4 after end of treatment). Samples for central laboratory testing were collected at protocol-specified time points for hematology, chemistry, biochemical markers of inflammation, and determination of antibodies against IL-10. All adverse events were graded for severity (mild, moderate, severe, or life-threatening) and assessed for any relationship with the administration of the study drug (unrelated, possibly related, probably related, related). Severe side effects were defined as incapacitating with inability to perform usual activities or as those that significantly affect clinical status warranting intervention. A serious adverse event has been defined as any event that is either fatal and/or life threatening (which is usually grade 4 according to World Health Organization classification), significantly or permanently disabling, requires patient hospitalization, or prolongs hospitalization or leads to congenital anomalies or birth defects. According to this definition, any hospitalization or prolonged hospital stay (also for reasons not related to $\mathrm{CD}$ or potential side effects of the study drug) was a serious adverse event. A serious adverse event is not necessarily severe.

\section{Immunologic Investigations}

Biopsy specimens were snap-frozen in liquid nitrogen at the time of removal and later crushed under liquid nitrogen and mechanically homogenized. During follow-up, attempts were made to collect biopsy specimens from the most inflamed and the least inflamed mucosal area in the same anatomic region. Nuclear and cytosolic extracts were prepared by adaptation of previously described techniques ${ }^{25-27}$ through freezethaw cycles on crushed ice. Cytosolic extracts were collected in an aqueous buffer containing $10 \mathrm{mmol} / \mathrm{L}$ HEPES ( $\mathrm{pH}$ 7.9) plus $1.5 \mathrm{mmol} / \mathrm{L} \mathrm{MgCl}_{2}$. Nuclear extracts were prepared by solubilizing the remaining nuclei in a second buffer containing 20 mmol/L HEPES ( $\mathrm{pH} 7.9$ ), $420 \mathrm{mmol} / \mathrm{L} \mathrm{NaCl}, 1.5 \mathrm{mmol} / \mathrm{L}$ $\mathrm{MgCl}_{2}, 0.2 \mathrm{mmol} / \mathrm{L}$ EDTA, and 25\% glycerol. Both buffers were supplemented with $1 \mathrm{mmol} / \mathrm{L}$ dithiothreitol, $0.5 \mathrm{mmol} / \mathrm{L}$ phenylmethylsulfonyl fluoride, $1 \mu \mathrm{g} / \mathrm{mL}$ aprotinin, $1 \mu \mathrm{g} / \mathrm{mL}$ leupeptin, $1 \mu \mathrm{g} / \mathrm{mL}$ pepstatin, $1 \mathrm{mmol} / \mathrm{L}$ benzamidine, 1 $\mathrm{mmol} / \mathrm{L}$ sodium vanadate, and $1 \mathrm{mmol} / \mathrm{L} \mathrm{NaF}$. The purity of the extract fractions was tested by marker proteins, which are exclusively expressed in one of the compartments ( $\mathrm{I} \kappa \mathrm{B} \alpha$ and fructose aldolase as markers for the cytosol and octamer transcription factor (OCT)-1 as a nuclear marker). ${ }^{28-30}$

For the assessment of total expression levels of the proteins studied, Western blot experiments were performed by using snap-frozen biopsy specimens that were lysed in boiling extraction buffer ( $1 \%$ sodium dodecyl sulfate, $10 \mathrm{mmol} / \mathrm{L}$ TRIS [pH 7.5], and $1 \mathrm{mmol} / \mathrm{L}$ sodium vanadate). Insoluble material was removed by centrifugation of samples for 5 minutes $(12,000 g)$ in an Eppendorf centrifuge (Eppendorf, Hamburg, Germany). Total protein concentration in a small aliquot of sample was assessed either by using the method of Lowry et al. ${ }^{31}$ or a modified Bradford protein assay (Bio-Rad, Munich, Germany), and all samples were adjusted to similar protein contents.

One to $10 \mu \mathrm{L}$ of cell lysate $(5-10 \mu \mathrm{g}$ total protein) was separated on a $12 \%$ denaturing polyacrylamide gel. Separated proteins were transferred to a polyvinylidene difluoride membrane (20 V, 75 minutes; transfer buffer: $25 \mathrm{mmol} / \mathrm{L}$ Tris, 190 $\mathrm{mmol} / \mathrm{L}$ glycine, $20 \% \mathrm{MeOH}$, and $0.5 \%$ sodium dodecyl sulfate) by electroblotter (Bio-Rad, Hercules, CA). The membrane was placed in blocking buffer ( $5 \%$ nonfat milk in 10 $\mathrm{mmol} / \mathrm{L}$ Tris $[\mathrm{pH} 7.5], 100 \mathrm{mmol} / \mathrm{L} \mathrm{NaCl}$, and $0.1 \%$ Tween 20; 60 minutes at ambient temperature). Blocking buffer was decanted, and the membrane was incubated with primary antibody (diluted in blocking buffer) on a shaker at ambient temperature (60 minutes). After washing (10 mmol/L Tris [pH 7.5], $100 \mathrm{mmol} / \mathrm{L} \mathrm{NaCl}$, and $0.1 \%$ Tween 20), the 
membrane was incubated with a peroxidase-conjugated secondary antibody. After washing, the membrane was placed in a hybridization bag containing Western View (Dianova/ Transduction Laboratories, Hamburg, Germany) working solution. The bands were quantified by densitometry (LumiImager; Boehringer-Mannheim, Mannheim, Germany). Results were recorrected after total protein (gold) staining of the blot. The results of this procedure are identical to total histone staining as shown previously. ${ }^{16}$

\section{Statistical Analysis}

Data on baseline characteristics of the patient population were tabulated and summarized by using descriptive statistics by treatment group. Comparability of treatment groups was evaluated by using 1-way analysis of variance (ANOVA) for the continuous variables and a $\chi^{2}$ test for the categoric variables. Safety data were listed, with the incidence of adverse experiences summarized by dose group, as were changes in World Health Organization grade from baseline in laboratory parameters.

The primary efficacy analysis was a comparison of CDAIbased clinical response rates for each rhuIL-10 dose with the rate for placebo by using the unadjusted $\chi^{2}$ test. Baseline hematocrit values were used in CDAI calculations to compensate for the dose-related decrease in hemoglobin concentration (and, hence, hematocrit) resulting from treatment with rhuIL-10 independent from disease activity. Data with $95 \%$ confidence intervals for each treatment group were calculated and used to further characterize the dose-response relationship. For the analysis of secondary endpoints, the $\chi^{2}$ test was used for pairwise comparisons of dichotomous variables and Fisher's exact test if subgroups became too small for the $\chi^{2}$ test. ${ }^{32}$ If indicated, results from multiple testing were adjusted by using Bonferroni corrections of $P$ values. All analyses are based on the intent-to-treat population.

Endoscopy findings were summarized by global assessment by study investigators (resolved, no change, worsening) and as change from baseline for the CDEIS score, respectively. Data with standard deviations were tabulated by dose group.

Results from immunologic tests were compared before and after treatment by using the Wilcoxon matched-pairs test ${ }^{33}$ or (for independent values) by using the Mann-Whitney $U$ test. ${ }^{32}$ All $P$ values are 2 -sided.

\section{Results}

\section{Study Population}

A total of 412 patients were screened for inclusion at 43 centers. Eighty-three patients were excluded in the screening phase for the following reasons: insufficient activity or documentation of disease $(n=30)$, subject's decision to withdraw consent during screening $(\mathrm{n}=15)$, excessive disease activity ( $\mathrm{n}=11$ ), unacceptable concomitant medication ( $\mathrm{n}=9$ ), abnormal laboratory test re- sults $(\mathrm{n}=8)$, history of cancer $(\mathrm{n}=4)$, hepatitis B or C infection ( $\mathrm{n}=3$ ), detection of signs of $C$. difficile infection $(n=2)$, and age outside the study limit $(n=1)$. The remaining 329 subjects were randomized to receive rhuIL-10 at doses of $1 \mu \mathrm{g} / \mathrm{kg}(\mathrm{n}=67), 4 \mu \mathrm{g} / \mathrm{kg}(\mathrm{n}=$ 64), $8 \mu \mathrm{g} / \mathrm{kg}(\mathrm{n}=65), 20 \mu \mathrm{g} / \mathrm{kg}(\mathrm{n}=67)$, or placebo ( $n=66$ ). Thirty-five centers enrolled up to 10 subjects, and 5 centers enrolled 10-27 subjects. Study population baseline demographics were well balanced with regard to sex, age, and disease characteristics (Table 1). Additionally, there were no significant differences between treatment groups in the use of concomitant therapies before initiation of study drug administration. The main recruiting center (S. Schreiber) received internal and external audits to control study conduct and compliance with Food and Drug Administration standards.

Eighty-six percent $(n=284)$ of the 329 randomized patients completed treatment. Forty-five patients were discontinued because of adverse events including the application of mandatory stopping rules (i.e., low thrombocyte counts) $(\mathrm{n}=30)$, treatment failure $(\mathrm{n}=9)$, protocol ineligibility $(\mathrm{n}=3)$, patient preference $(\mathrm{n}=2)$, and death $(\mathrm{n}=1)$. Three protocol-ineligible patients were randomized but received no study drug. A total of 316 patients (96\% of those randomized) completed the follow-up phase. The mean number of treatment days was $26.1 \pm 5.3$ (mean \pm SD) for patients receiving IL-10 and $27.4 \pm 4.2$ for patients receiving placebo. More than $99 \%$ of the planned doses of study drug were administrated by the patients.

\section{Safety}

Adverse events. Overall, 95\% of the patients who received rhuIL-10 and $94 \%$ of patients treated with placebo experienced at least 1 adverse event during the treatment and/or follow-up phase of the study. Most adverse events occurred with similar frequencies in rhuIL-10 - and placebo-treated patients (Table 2). Some events, such as headache $(P=0.02)$, fever $(P=0.02)$, back pain $(P=0.01)$, decrease in hemoglobin concentration $(P=0.0007)$, dizziness $(P=0.005)$, and thrombocytopenia ( $P=0.0006$ ) occurred more frequently in the high-dose rhuIL-10 group $(20 \mu \mathrm{g} / \mathrm{kg})$ than the placebo population (uncorrected $P$ values).

Most of the adverse events were graded by the investigators as mild or moderate in severity. Severe adverse events were reported in 28\% (74 of 263) of patients who received rhuIL-10 and $17 \%$ (11 of 66) of those receiving placebo $(P=0.057)$. Serious adverse events were experienced by $31 \%$ (81 of 263) of rhuIL-10treated patients and by $27 \%$ (18 of 66) of placebo-treated patients. Asymptomatic transient lymphopenia was the 
Table 1. Patient Characteristics

\begin{tabular}{|c|c|c|c|c|c|c|}
\hline & \multicolumn{5}{|c|}{ rhulL-10 } & \multirow[b]{2}{*}{$\begin{array}{l}\text { Placebo } \\
(\mathrm{n}=66)\end{array}$} \\
\hline & $\begin{array}{l}1 \mu g / k g \\
(n=67)\end{array}$ & $\begin{array}{l}4 \mu g / k g \\
(n=64)\end{array}$ & $\begin{array}{l}8 \mu g / k g \\
(n=65)\end{array}$ & $\begin{array}{l}20 \mu \mathrm{g} / \mathrm{kg} \\
(\mathrm{n}=67)\end{array}$ & $\begin{array}{l}\text { All doses } \\
(n=263)\end{array}$ & \\
\hline Sex: male [n (\%)] & $32(48)$ & $30(47)$ & $32(49)$ & $29(43)$ & $123(47)$ & $31(47)$ \\
\hline Age $(y r$, mean $\pm \mathrm{SD})$ & $33.8 \pm 10.4$ & $33.3 \pm 10.6$ & $34.1 \pm 10.7$ & $36 \pm 11.7$ & $34.3 \pm 10.9$ & $34.1 \pm 10.4$ \\
\hline \multicolumn{7}{|l|}{ Duration of disease } \\
\hline$(y r$, mean $\pm \mathrm{SD})$ & $7.3 \pm 5.6$ & $7.4 \pm 6.6$ & $8.8 \pm 6.8$ & $10.2 \pm 8.4$ & $8.5 \pm 7.0$ & $7.7 \pm 7.2$ \\
\hline Previous resections [n (\%)] & $29(43)$ & $29(45)$ & $26(40)$ & $28(42)$ & $112(42)$ & $32(48)$ \\
\hline \multicolumn{7}{|l|}{ Extraintestinal manifestations ${ }^{a}$} \\
\hline$[n(\%)]$ & $40(60)$ & $40(63)$ & $33(51)$ & $45(67)$ & $158(60)$ & $40(61)$ \\
\hline Anal disease or fistulas [n (\%)] & $22(33)$ & $15(23)$ & $15(23)$ & $23(34)$ & $75(29)$ & $21(32)$ \\
\hline Baseline CDAI (median) & 266 & 257 & 282 & 275 & 271 & 271 \\
\hline Immunomodulator use ${ }^{b}[\mathrm{n}(\%)]$ & $18(27)$ & $15(23)$ & $15(23)$ & $19(28)$ & $67(25)$ & $15(23)$ \\
\hline \multicolumn{7}{|l|}{ Other immunosuppressives ${ }^{c}$} \\
\hline [n (\%)] & $0(0)$ & $1(2)$ & $3(5)$ & $1(1)$ & $5(2)$ & $1(2)$ \\
\hline Antibiotics [n (\%)] & $13(19)$ & $8(13)$ & $15(23)$ & $9(13)$ & $45(17)$ & $6(9)$ \\
\hline Mesalamine $[\mathrm{n}(\%)]^{d}$ & $45(67)$ & $32(50)$ & $48(74)$ & $53(79)$ & $178(68)$ & $37(56)$ \\
\hline $\begin{array}{l}\text { Glucocorticoid dose (mg/day, } \\
\text { mean } \pm \text { SD) }\end{array}$ & $16.6 \pm 7.4$ & $17.2 \pm 9.1$ & $17.8 \pm 7.6$ & $17.0 \pm 8.2$ & $17.2 \pm 8.1$ & $17.9 \pm 7.4$ \\
\hline
\end{tabular}

${ }^{a}$ Arthritis/arthralgia, uveitis/iritis, skin.

${ }^{b}$ Azathioprine, 6-mercaptopurine.

${ }^{c}$ Cyclosporine, methotrexate.

dPairwise comparisons were performed against placebo by using the Fisher exact test: $1 \mu \mathrm{g} / \mathrm{kg} ; P=0.21 ; 4 \mu \mathrm{g} / \mathrm{kg}, P=0.59 ; 8 \mu \mathrm{g} / \mathrm{kg}$, $P=0.04 ; 20 \mu \mathrm{g} / \mathrm{kg}, P=0.02 ;$ all doses, $P=0.09$.

most common serious adverse event reported in 25 of $263(9.5 \%)$ of rhuIL-10-treated patients and in 6 of 66 (9\%) placebo-treated patients. One death occurred in a patient who received rhuIL-10. The patient had undergone multiple coronary artery bypass surgeries and died of acute cardiac infarction. His death was attributed to the underlying severe coronary heart disease without any relationship to the study drug as classified by the clinical investigator.

Hematologic changes. A dose-dependent decrease in hemoglobin/hematocrit and platelet counts was observed in patients treated with high doses of rhuIL-10 (8 and $20 \mu \mathrm{g} \cdot \mathrm{kg}^{-1} \cdot \mathrm{day}^{-1}$ ). The mechanism of this side effect remains unknown.

Table 2. Most Frequent Adverse Events

\begin{tabular}{|c|c|c|c|c|c|c|c|}
\hline \multirow[b]{2}{*}{ Type of adverse event [n (\%)] } & \multicolumn{6}{|c|}{ rhulL-10 } & \multirow[b]{2}{*}{$\begin{array}{l}\text { Placebo } \\
(\mathrm{n}=66)\end{array}$} \\
\hline & $\begin{array}{c}\text { Frequency } \\
\quad(\text { rank })^{a}\end{array}$ & $\begin{array}{c}1 \mu g / k g \\
(\mathrm{n}=67)\end{array}$ & $\begin{array}{l}4 \mu g / k g \\
(n=64)\end{array}$ & $\begin{array}{l}8 \mu \mathrm{g} / \mathrm{kg} \\
(\mathrm{n}=65)\end{array}$ & $\begin{array}{c}20 \mu g / k g \\
(n=67)\end{array}$ & $\begin{array}{l}\text { All doses } \\
(\mathrm{n}=263)\end{array}$ & \\
\hline Any adverse event & & $63(94)$ & $57(89)$ & $62(95)$ & $67(100)$ & $249(95)$ & $62(94)$ \\
\hline Headache & 1 & $28(42)$ & $20(31)$ & $28(43)$ & $44(66)$ & $120(46)$ & $30(45)$ \\
\hline Abdominal pain & 2 & $25(37)$ & $16(25)$ & $25(38)$ & $24(36)$ & $90(34)$ & $17(26)$ \\
\hline Fever & 3 & $14(21)$ & $17(27)$ & $14(22)$ & $22(33)$ & $67(25)$ & $11(17)$ \\
\hline Fatigue & 4 & $9(13)$ & $12(19)$ & $21(32)$ & $24(36)$ & $66(25)$ & $17(26)$ \\
\hline Nausea & 5 & $16(24)$ & $14(22)$ & $11(17)$ & $24(36)$ & $65(25)$ & $16(24)$ \\
\hline Lymphopenia & 6 & $19(28)$ & $17(27)$ & $9(14)$ & $14(21)$ & $59(22)$ & $13(20)$ \\
\hline Arthralgia & 7 & $16(24)$ & $10(16)$ & $15(23)$ & $16(24)$ & $57(22)$ & $11(17)$ \\
\hline Back pain & 8 & $10(15)$ & $9(14)$ & $13(20)$ & $16(24)$ & $48(18)$ & $6(9)$ \\
\hline Decrease in hemoglobin ${ }^{b}$ & 9 & $8(12)$ & $7(11)$ & $7(11)$ & $22(33)$ & $44(17)$ & $5(8)$ \\
\hline Viral infection & 10 & $10(15)$ & $10(16)$ & $8(12)$ & $12(18)$ & $40(15)$ & $5(8)$ \\
\hline Myalgia & 11 & $5(7)$ & $9(14)$ & $10(15)$ & $11(16)$ & 35 (13) & $6(9)$ \\
\hline Injection site reaction & 12 & $9(13)$ & $10(16)$ & $7(11)$ & $6(9)$ & $32(12)$ & $9(14)$ \\
\hline Dizziness & 14 & $5(7)$ & $4(6)$ & $7(11)$ & $14(21)$ & $30(11)$ & $3(5)$ \\
\hline Musculoskeletal pain & 17 & $10(15)$ & $2(3)$ & $4(6)$ & $12(18)$ & $28(11)$ & 7 (11) \\
\hline Thrombocytopenia & 25 & $0(0)$ & $0(0)$ & $3(5)$ & $11(16)$ & $14(5)$ & $0(0)$ \\
\hline
\end{tabular}

NOTE. The table lists the number of patients and percentages [n (\%)].

aRanked by cumulated frequency in all IL-10 dose groups.

${ }^{b}$ Mean decrease in hematocrit was 1\%, $0.7 \%, 2.9 \%$, and $1.3 \%$ in the 1, 4, 8, and $20 \mu \mathrm{g} / \mathrm{kg}$ and the placebo groups, respectively. 
Decreases in hemoglobin occurred in 11\% (22/196) of patients at the $1-, 4-$, and $8-\mu \mathrm{g} / \mathrm{kg}$ rhuIL-10 groups and in $8 \%(5 / 66)$ of placebo patients. A greater frequency of drug-induced decreases in hemoglobin concentrations was observed in the $20-\mu \mathrm{g} / \mathrm{kg}$ rhuIL-10 group with 22 of $67(33 \%)$ patients experiencing a decrease in hemoglobin concentrations ( $P=0.0003$ vs. placebo) and $25 \%$ (17/ 67) experiencing anemia (defined as hemoglobin values $<95 \mathrm{~g} / \mathrm{L}$ ). Increases in reticulocyte counts were correlated with changes in hemoglobin concentration, suggesting a regeneration phenomenon. Thrombocytopenia, defined as a platelet count of $<100,000 / \mathrm{mm}^{3}$, was reported exclusively at the 2 highest dose levels of rhuIL-10 $(6 \%[4 / 65]$ in the $8-\mu \mathrm{g} / \mathrm{kg}$ group $\lfloor P=0.04$ vs. placebo $]$ and $27 \%[18 / 66]$ in the $20-\mu \mathrm{g} / \mathrm{kg}$ group $[P<$ 0.0001 vs. placebo]). Decreases in thrombocyte counts, hemoglobin, and increases in reticulocyte counts fully reverted to normal levels during follow-up or within days after cessation of the study drug. No clinically relevant differences were noted between rhuIL-10-treated and placebo patients for any other change in laboratory parameter values.

Withdrawals. Discontinuation of treatment because of adverse events or adverse events associated with treatment failure occurred most frequently in the 20$\mu \mathrm{g} / \mathrm{kg}$ rhuIL-10 dose group. At this dose, 30\% (20/67; $P<0.0001$ vs. placebo) of patients discontinued treatment compared with $8 \%(16 / 196)$ of patients receiving lower doses of rhuIL-10 and 3\% (2/66) of patients receiving placebo. The most frequent adverse event that resulted in discontinuation was thrombocytopenia (mandatory stopping at thrombocyte counts of $\leq 100,000 /$ $\mathrm{mm}^{3}$ ). Eight of 329 patients discontinued treatment because of asymptomatic thrombocytopenia $(8 \mu \mathrm{g} / \mathrm{kg}$, $1 / 65 ; 20 \mu \mathrm{g} / \mathrm{kg} ; 7 / 67)$. Thrombocytopenia was reversible in all cases within 1 week of discontinuation of study drug. Five of 329 patients discontinued because of headache, 4 of whom were in the $20-\mu \mathrm{g} / \mathrm{kg}$ group. No clinically significant problems remained from the adverse events.

\section{Treatment Efficacy}

Induction of remission. The primary efficacy endpoint was the induction of clinical remission. Induction of remission was observed in 12 (18\%; $95 \%$ confidence interval, 9.6-\%29.2\%) patients treated with $1 \mu \mathrm{g} / \mathrm{kg}$ $(P=0.85$ vs. placebo), in $14(22 \%, 12.5-34)$ treated with $4 \mu \mathrm{g} / \mathrm{kg}(P=0.45)$, in $7(11 \%, 4.4-21)$ treated with $8 \mu \mathrm{g} / \mathrm{kg}(P=0.32)$, in $7(10 \%, 4.3-20.4)$ treated with $20 \mu \mathrm{g} / \mathrm{kg}(P=0.43)$, and in $11(17 \%, 8.6-27.9)$ placebo-treated patients. Because the administration of rhuIL-10 was associated with a decrease in hematocrit between $1 \%$ and $5 \%$ at the higher doses as part of its biologic effects (Table 2), the CDAI scores on day 29 were calculated by using the baseline hematocrit (baseline-adjusted hematocrit value). This method was chosen because IL-10 itself alters hemoglobin values independent from its potential effects on inflammation. Remission rates for rhuIL-10 were after correction $12(18 \%$, 9.6-29.2; $P=0.79), 13(20 \%, 11.3-32.2 ; P=0.76)$, $13(20 \%, 11.1-31.8 ; P=0.76), 19(28 \%, 18-40.7$; $P=0.17)$, respectively, in comparison with $12(18 \%$, 9.6-29.6) in the placebo group. Based on the protocolspecified definition of remission (drop of CDAI by at least 100 points to values less than 150 points), it was not possible to detect a beneficial effect of rhuIL-10 over placebo.

Clinical improvement. Clinical improvement defined as a reduction of the CDAI of at least 100 points was observed more frequently in the rhuIL-10 groups than in the placebo group, although overall statistical significance was not achieved. The effect across all rhuIL-10 dose groups (97 improved patients $[37 \%, 31-$ 43]) resulted in an overall significance level $(P=0.14)$ compared with placebo (18 [27\%, 17-39.6]) by using the baseline-adjusted hematocrit for the calculation of the CDAI. The dose of $1 \mu \mathrm{g} / \mathrm{kg}$, which had no efficacy in vitro, in previous trials as well as in this study, had been included into the design to cover the lower end of the expected dose-response curve. For the exploratory analysis, the combined $1 \mu \mathrm{g} / \mathrm{kg}$-placebo population (resulting in $36[27 \%, 19.7-35.5]$ improved patients) was compared with the remaining active dose groups $(4,8$, and $20 \mu \mathrm{g} / \mathrm{kg} ; 79$ patients [40\%, 33.4-47.5]), which resulted in a $P=0.014$. Exploratory pairwise comparisons resulted in a $P=0.03$ value between the $8-\mu \mathrm{g}$ rhuIL$10 / \mathrm{kg}$ and the placebo group (Figure 1).

In addition to the clinical endpoints, duration of response was analyzed post hoc in an exploratory analysis. The duration of remission or clinical improvement was evaluated from the time the patient began to respond. The percentage of patients showing a duration of response of at least 4 weeks is shown in Figure 2. This exploratory analysis suggested that the $8-\mu \mathrm{g}$ rhuIL$10 / \mathrm{kg}$ dose group was different from the $1-\mu \mathrm{g} / \mathrm{kg}$ dose group $(P=0.0033)$, the $20-\mu \mathrm{g} / \mathrm{kg}$ group $(P=0.013)$, and the placebo group ( $P=0.0020$; Figure 2$)$. After Bonferroni corrections, the statistical difference between the $8-\mu \mathrm{g} / \mathrm{kg}$ group and the placebo group as well as the $1-\mu \mathrm{g} / \mathrm{kg}$ group, respectively, remained.

Subgroup analysis. Clinical subgroup analysis suggested that patients with high disease activity (i.e., above the median CDAI of the study population) had a 


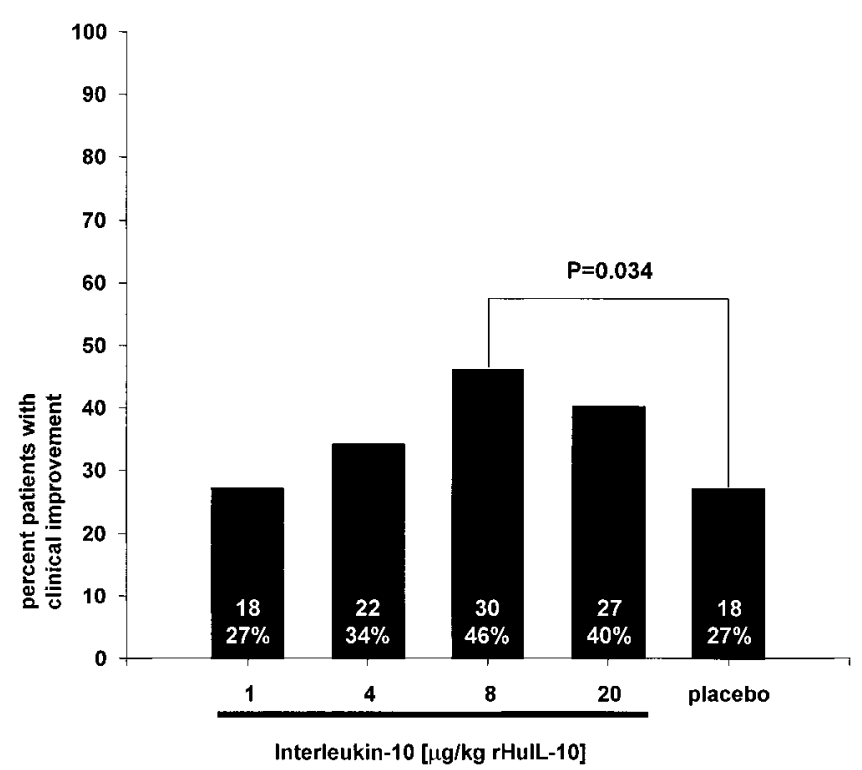

Figure 1. Clinical improvement (reduction in the CDAl by at least 100 points). Data are calculated by using the baseline-adjusted hematocrit and show the intent-to-treat population. Statistical significance was calculated by the $\chi^{2}$ test. The number and percentage of patients showing clinical improvement are indicated within the bars.

greater rate of clinical improvement after treatment with rhuIL-10 than those with low disease activity. The analysis shown in Figure 3 used the median baseline CDAI in the study population ( 275 points) to define subgroups. The exploratory analysis resulted in an uncorrected $P$

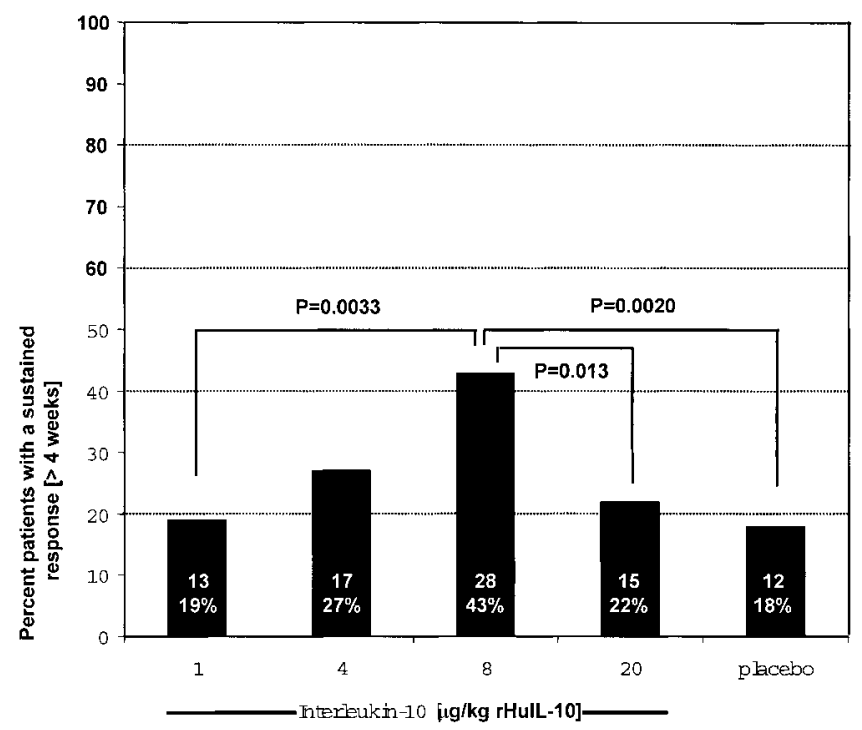

Figure 2. Induction of a response (remission or clinical improvement) of at least 4 weeks' duration at any time. Data are calculated by using the baseline hematocrit and show the intent-to-treat population. The number and percentage of patients responding are indicated within the bars. Noncorrected significance levels are indicated for pairwise comparisons. The 95\% confidence intervals for the groups were as follows: $1 \mu \mathrm{g} / \mathrm{kg}, 10.8-30.9$; $4 \mu \mathrm{g} / \mathrm{kg}, 16.3-39.2 ; 8 \mu \mathrm{g} / \mathrm{kg}, 30.9-$ $56 ; 20 \mu \mathrm{g} / \mathrm{kg}, 13.1-34.2$; placebo, 9.6-29.6.

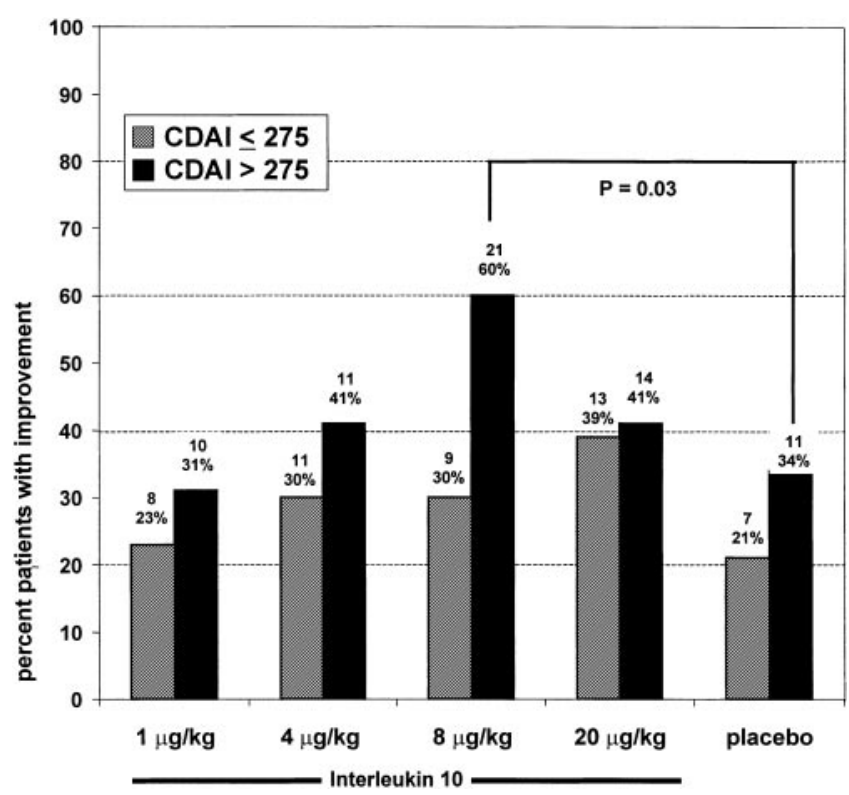

Figure 3. Induction of clinical improvement is dependent on disease activity. Data are calculated by using the baseline-adjusted hematocrit and show the intent-to-treat population. The number and percentage of patients with clinical improvement are indicated above the bars. The median CDAI in the study population (275) has been used to divide patient subgroups. The data are not corrected for steroid use, which had a much weaker effect than CDAl or other activityrelated parameters (see Table 3 ). The exploratory analysis results in an uncorrected $P$ value of 0.03 ( $\chi^{2}$ test) for a comparison between clinical improvement in the $8-\mu \mathrm{g} / \mathrm{kg}$ group with placebo. The overall analysis by logistic regression showed an influence of disease activity but not treatment group. $\mathbb{V}_{/ /}, \mathrm{CDAI} \leq 275 ; \mathbf{\square}, \mathrm{CDAI}>275$.

value of 0.03 ( $\chi^{2}$ test) when clinical improvement in the $8-\mu \mathrm{g} / \mathrm{kg}$ group (21 patients improving, $60 \%$ ) and the placebo group (11 improvements, 34\%; Figure 3) were compared. Logistic regression was performed, which resulted in $P$ values of 0.01 (Wald $X^{2}, 3.43$ ) for the influence of the CDAI and of 0.064 (Wald $\chi^{2}, 6.63$ ) for the influence of study drug dose. After inclusion of an interaction term between categoric CDAI $(\leq$ or $>275)$ and the study drug dose, the logistic regression model resulted in an overall $P$ value of 0.45 (Wald $\chi^{2}, 0.55$ ), now giving a $P$ value of 0.018 for the influence of the CDAI (Wald $\chi^{2}, 5.6$ ) and of 0.4 for the influence of study drug dose (Wald $\chi^{2}, 0.69$ ). A similar trend, with more active patients showing a better response, was also seen with various other activity-related parameters, which included baseline white blood cell count, baseline C-reactive protein, baseline $\mathrm{CD}$ management (glucocorticoid dose, medication with azathioprine/6-mercaptopurine), duration of $\mathrm{CD}$ (Table 3), baseline abdominal pain (data not shown), and baseline general well-being (data not shown).

The increased placebo response rate that was detected in the high-CDAI group in comparison with the low- 
Table 3. Activity-Related Clinical Parameters and Clinical Improvement in Response to rhulL-10

\begin{tabular}{|c|c|c|c|c|c|}
\hline & \multicolumn{4}{|c|}{ rhulL-10 } & \multirow[b]{2}{*}{$\begin{array}{l}\text { Placebo } \\
(\mathrm{n}=66)\end{array}$} \\
\hline & $\begin{array}{l}1 \mu g / k g \\
(n=67)\end{array}$ & $\begin{array}{l}4 \mu g / k g \\
(n=64)\end{array}$ & $\begin{array}{l}8 \mu g / k g \\
(n=65)\end{array}$ & $\begin{array}{c}20 \mu \mathrm{g} / \mathrm{kg} \\
(\mathrm{n}=67)\end{array}$ & \\
\hline Total population & $18(27)$ & $22(34)$ & $30(46)$ & $27(40)$ & $18(27)$ \\
\hline \multicolumn{6}{|l|}{ CDAI } \\
\hline$\leq 275$ & $8(23)$ & $11(30)$ & $9(30)$ & $13(39)$ & 7 (21) \\
\hline$>275$ & $10(31)$ & $11(41)$ & $21(60)$ & $14(41)$ & $11(34)$ \\
\hline \multicolumn{6}{|l|}{ White blood cell count } \\
\hline$\leq 10.7 \times 10^{9} / \mathrm{L}$ & $8(24)$ & $10(26)$ & $16(42)$ & $14(33)$ & $12(30)$ \\
\hline$>10.7 \times 10^{9} / \mathrm{L}$ & $10(29)$ & $11(44)$ & $14(61)$ & $13(52)$ & $6(23)$ \\
\hline Missing & 0 & 1 & 0 & 0 & 0 \\
\hline \multicolumn{6}{|l|}{ C-reactive protein } \\
\hline$<1.6 \mathrm{mg} / \mathrm{L}$ & $9(26)$ & $8(30)$ & $11(37)$ & $13(38)$ & $8(24)$ \\
\hline$\geq 1.6 \mathrm{mg} / \mathrm{L}$ & $9(29)$ & $14(39)$ & $19(56)$ & $14(45)$ & $9(30)$ \\
\hline Missing & 0 & 0 & 0 & 0 & 1 \\
\hline \multicolumn{6}{|l|}{ Baseline medication } \\
\hline Glucocortocoids only & $12(25)$ & $20(42)$ & $21(42)$ & $19(42)$ & $15(29)$ \\
\hline Azathioprine/6-mercaptopurine & $6(33)$ & $2(13)$ & $9(60)$ & $8(42)$ & $3(21)$ \\
\hline \multicolumn{6}{|l|}{ Duration of $C D$} \\
\hline$<7$ yr (median) & $10(29)$ & $14(40)$ & $18(55)$ & $10(38)$ & $11(30)$ \\
\hline$\geq 7 \mathrm{yr}$ & $8(25)$ & $8(29)$ & $12(38)$ & $17(41)$ & $7(25)$ \\
\hline
\end{tabular}

NOTE. Hematocrit-adjusted CDAI scores were calculated in the intent-to-treat population. Data show the number of patients who showed improvement or remission and corresponding percentage [n (\%)].

CDAI group was not seen in most of the other activityrelated parameters that were used to define patient subgroups (Table 3).

Endoscopic evaluation. Endoscopic evaluation of a subset of 104 patients showed that resolution and improvement of lesions occurred in 50 of 81 rhuIL-10 treated patients $(62 \%, 50.3-72.3)$ in comparison with 10 of 23 placebo-treated patients (43\%, 23.3-65.5; $P=$ $0.15)$. A trend was seen in that a greater proportion of rhuIL-10-treated than placebo-treated patients experienced both improvement/remission and a decrease in the severity of endoscopic findings, with the greatest effect observed in the $8-\mu \mathrm{g} / \mathrm{kg}$ group (10/22 patients $[45 \%$, $24.4-67.8]$ vs. placebo, 5 of $23[22 \%, 7.5-43.7]$; $P=0.12)$.

Although not statistically significant, the median change in the CDEIS among improved patients and patients in remission (Figure 4) was higher in the group of patients who received $8 \mu \mathrm{g} / \mathrm{kg}$ rhuIL-10 $(-74.1 \%)$ or $20 \mu \mathrm{g} / \mathrm{kg}(-54.1 \%)$ than that in the placebo group $(-26.3 \%)$. The same pattern of dose response was observed in the endoscopic score at a lower level in the nonresponder group (change of CDEIS, $-4.7 \%,-3.0 \%$, $-22.8 \%$, and $0 \%$ for $1,4,8$, and $20 \mu \mathrm{g} / \mathrm{kg}$ rhuIL-10 vs. $-12.9 \%$ for placebo). Overall changes in CDEIS scores were $-11.5,-15.3,-46.4,-21.4 \%$ in the active treatment groups and $-16.1 \%$ in the placebo cohort.

Health-related QOL. Both the SF3634 and the IBDQ $^{35}$ were used to assess changes in health-related
QOL during treatment. The SF36 contains 8 scales that can be combined into 2 summary scales: summary physical and summary mental health scale scores. ${ }^{34,36}$ The sample size, which was determined by the CDAI-based primary endpoint of the study (see Patients and Methods), was not giving sufficient power to detect minimally important clinical changes in SF36 (at least 10 points) or IBDQ (at least 16 points) scores. No significant difference between treatment groups was seen by ANOVA at any of the time points (day 15 and treatment endpoint)

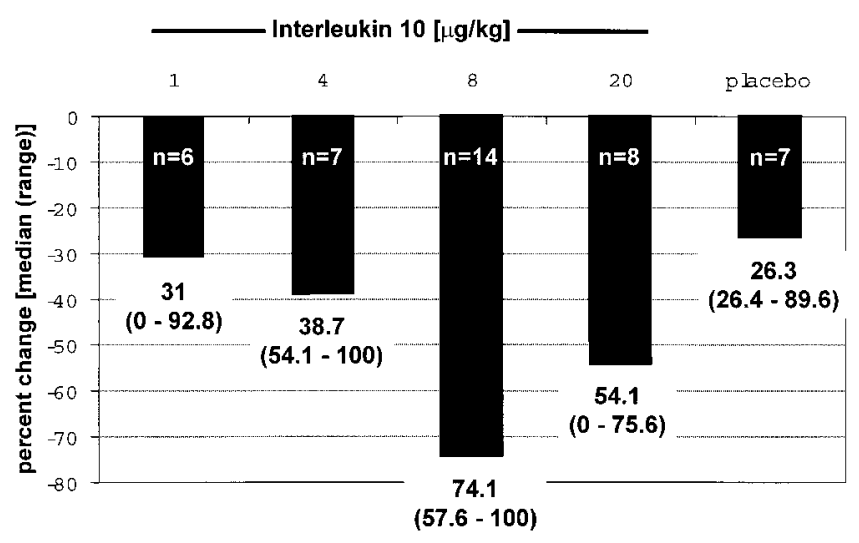

Figure 4. Change in the endoscopic index of severity (CDEIS) in the responder population (clinical improvement and remission). The median change of the CDEIS and its range (\%) is indicated below the bars; the number of patients is indicated within the bars. Data show responders in the intent-to-treat population. Differences are not statistically significant. 
Table 4. Baseline Scores and Mean Change to Treatment Endpoint for Health-Related QOL Scores

\begin{tabular}{|c|c|c|c|c|c|}
\hline & \multicolumn{4}{|c|}{ rhulL-10 } & \multirow[b]{2}{*}{$\begin{array}{l}\text { Placebo } \\
(n=66)\end{array}$} \\
\hline & $\begin{array}{l}1 \mu g / k g \\
(n=67)\end{array}$ & $\begin{array}{l}4 \mu g / k g \\
(n=64)\end{array}$ & $\begin{array}{l}8 \mu \mathrm{g} / \mathrm{kg} \\
(\mathrm{n}=65)\end{array}$ & $\begin{array}{l}20 \mu g / k g \\
(n=67)\end{array}$ & \\
\hline \multicolumn{6}{|l|}{ IBDQ } \\
\hline Baseline & $134 \pm 27$ & $140 \pm 28$ & $133 \pm 28$ & $134 \pm 27$ & $133 \pm 27$ \\
\hline Change to treatment endpoint & $\begin{array}{l}21 \pm 30 \\
(14-28)\end{array}$ & $\begin{array}{l}16 \pm 22 \\
(10-21)\end{array}$ & $\begin{array}{l}15 \pm 21 \\
(10-20)\end{array}$ & $\begin{array}{l}17 \pm 24 \\
(11-23)\end{array}$ & $\begin{array}{l}18 \pm 25 \\
(12-24)\end{array}$ \\
\hline \multicolumn{6}{|l|}{ SF36 physical scale scores } \\
\hline Baseline & $35 \pm 8.9$ & $38 \pm 9$ & $35 \pm 9.1$ & $34 \pm 8.7$ & $36 \pm 7.1$ \\
\hline Change to treatment endpoint & $\begin{array}{l}4.7 \pm 8.6 \\
(2.5-6.9)\end{array}$ & $\begin{array}{l}3.1 \pm 6.5 \\
(1.5-4.8)\end{array}$ & $\begin{array}{l}3.5 \pm 5.9 \\
(2.0-5.1)\end{array}$ & $\begin{array}{l}3.2 \pm 8.8 \\
(1.0-5.5)\end{array}$ & $\begin{array}{l}4.3 \pm 6.0 \\
(2.8-5.9)\end{array}$ \\
\hline \multicolumn{6}{|l|}{ SF 36 mental health scale scores } \\
\hline Baseline & $40 \pm 12$ & $40 \pm 11$ & $39 \pm 10$ & $42 \pm 12$ & $39 \pm 11$ \\
\hline Change to treatment endpoint & $\begin{array}{l}3.8 \pm 10.9 \\
(1.0-6.5)\end{array}$ & $\begin{array}{l}3.5 \pm 8.9 \\
(1.2-5.7)\end{array}$ & $\begin{array}{l}0.4 \pm 10.0 \\
(-2.2-3.1)\end{array}$ & $\begin{array}{c}0.7 \pm 9.8 \\
(-1.7-3.2)\end{array}$ & $\begin{array}{c}32 \pm 9.9 \\
(0.6-5.7)\end{array}$ \\
\hline
\end{tabular}

NOTE. Data for SF36 and IBDQ are means \pm SD, with 95\% confidence intervals for changes in parentheses.

as shown in Table 4. Nominal improvement was seen in all groups including the placebo population. Most of the improvements seen occurred by day 15 (Table 4).

In general, the health-related QOL results were consistent with the clinical activity scores. The largest change in IBDQ scores was observed among subjects who reached clinical remission (decrease of the CDAI by $\geq 100$ points to values $<150$ points at treatment endpoint, $\mathrm{n}=50$; mean change in score, 35.1 points). Clinical improvement (decrease in CDAI by $\geq 100$ points but values $\geq 150$ points at treatment endpoint) was accompanied by a mean decrease in the IBDQ score of 28.5 points $(\mathrm{n}=43)$, followed by those patients who reached a CDAI $<150$ points at treatment endpoint but no drop of at least 100 points (mean change in IBDQ scores of 23.0 points, $\mathrm{n}=15$ ). More interestingly, the IBDQ score also improved in patients who failed to respond to treatment based on the CDAI (mean improvement of IBDQ scores of 10.3 points, $\mathrm{n}=215$ ).

\section{Therapeutic Mechanism of rhulL-10}

Transcription factor activation in intestinal lamina propria biopsy specimens was assessed in 50 consecutive patients from 7 previously selected European sites. The activation status of the transcription factor NF- $\kappa B$ system is reflected by the availability of its main cytoplasmatic inhibitory IкB $\alpha$ as well as the nuclear concentration of the NFкB p65 subunit. Nuclear proteins were quantitatively extracted from biopsy specimens of (ileo) colonic mucosa showing little or no macroscopic signs of inflammation. NF- $\kappa B$ p 65 concentrations were assessed in nuclear extracts and IкB $\alpha$ levels in total extracts. Patients treated with rhuIL-10 experiencing clinical improvement or remission $(\mathrm{n}=10)$ and nonresponders $(n=27)$ greatly differed with regard to changes in the
NF-кB system. In patients experiencing improvement/ remission, nuclear concentrations of the NF- $\mathrm{BB}$ p 65 protein were reduced (from $1.0[0.76-1.4]$ to 0.28 $[0-0.45]$, arbitrary units, data as median [interquartile range]; $P=0.009$, Wilcoxon matched-pairs analysis; $\mathrm{n}=10$; Figure $5 A$ ) and total concentration of $\mathrm{I \kappa B} \alpha$ increased (from $5.5[1.4-7.6]$ to $12.9[1.9-21.96] ; P=$ $0.046, \mathrm{n}=10)$. In nonresponders to rhuIL-10 $(\mathrm{n}=27)$, levels of NF-кB p65 (before, 0.23 [0-3.6]; after, 0.57 $[0-4.4] ; P=0.25, \mathrm{n}=15)$ as well as total I $\mathrm{I} \mathrm{B} \alpha$ levels (before, 7.8 [3.5-12.2]; after, 8.5 [4.1-14.0]; $P=0.19$, $\mathrm{n}=27)$ remained stable. Patients who received placebo $(\mathrm{n}=13)$ exhibited no change in IкB $\alpha$ levels (before, 4.6 [3.17-10.8]; after, 5.3 [3.07-6.94]; $P=0.2$ ) but showed a significant increase in nuclear concentrations of NF-кB p65 (from $0.97[0.3-1.45]$ to $1.1[0.7-5.1] ; P=$ 0.03). Placebo-treated and rhuIL-10-treated patients did not differ in pretreatment levels of nuclear NF- $\kappa \mathrm{B}$ p65 (0.97 [0.3-1.45] and $0.75[0.25-1.57] ; P=0.84)$. After treatment, levels of NF-KB p65 were lower in rhuIL-10-treated patients $(0.45[0.09-0.86])$ than the placebo group (1.1 [0.7-5.1]; $P=0.009$, Mann-Whitney $U$ test).

\section{Discussion}

Subcutaneous administration of rhuIL-10 in doses of 1,4 , or $8 \mu \mathrm{g} / \mathrm{kg}$ body wt for 28 consecutive days has been shown to be safe and well tolerated in patients with chronic active CD. The excellent patient compliance reflects both the good local and systemic tolerance to rhuIL-10. Adverse events frequently reported with rhuIL-10 (which cumulate in the $20-\mu \mathrm{g} / \mathrm{kg}$ dose group) include mild-to-moderate headache, fever, back pain, and dizziness. Moderate decreases in hemoglobin concen- 

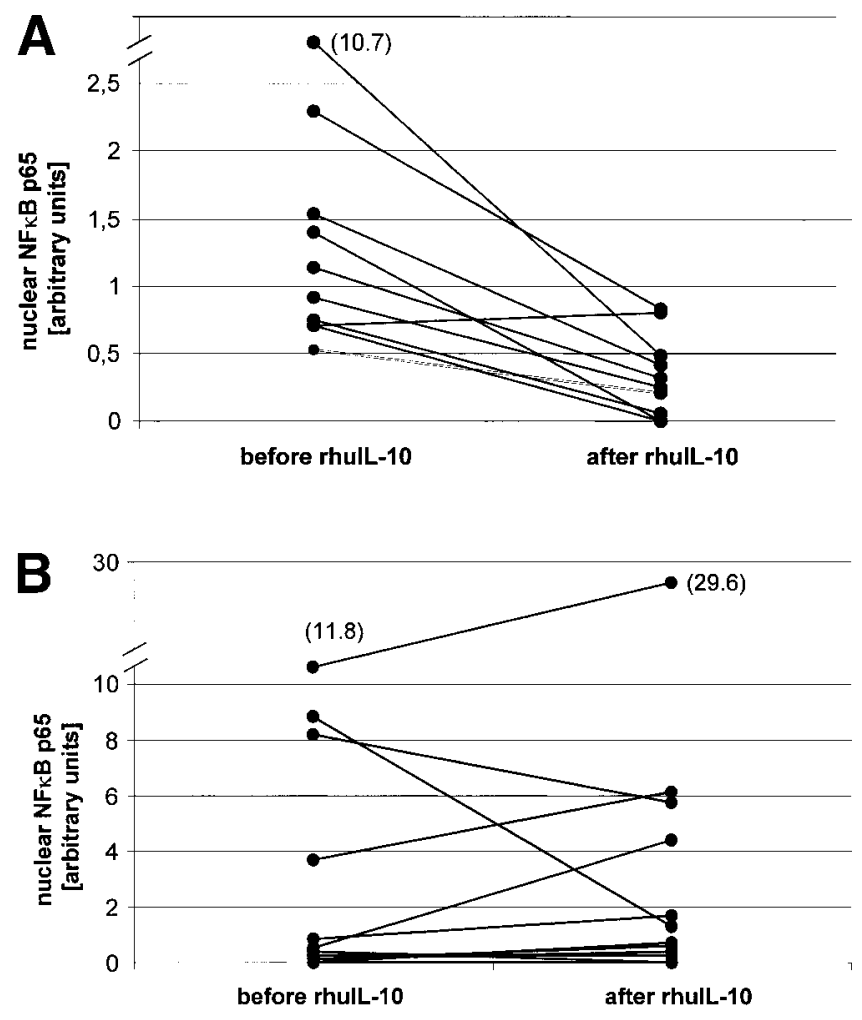

Figure 5. Clinical response (clinical improvement and remission) to rhulL-10 treatment is accompanied by a decrease in nuclear concentrations of NF-кB p65 (NF-кB p65; $P=0.009, \mathrm{n}=10 ; A$ ). Patients showing no response show unchanged nuclear levels of NF-kB p65 $(P=0.25, \mathrm{n}=15 ; B)$ and unaltered total concentrations of $\mathrm{I}_{\kappa} \mathrm{B} \alpha(P=$ $0.19, \mathrm{n}=27$, not shown). Statistical comparisons are by Wilcoxon matched-pairs test. All values are expressed in arbitrary units, which were standardized with a HT29 cell line extract.

trations and platelet counts were observed in the 8- and $20-\mu \mathrm{g} / \mathrm{kg}$ rhuIL-10 dose groups. These hematologic changes were mostly asymptomatic, transient, and readily reversible after treatment. No rebound in disease activity was detected in any patient after withdrawal of the study drug. No production of antibodies to rhuIL-10 was found in any laboratory investigation during treatment and follow-up.

The frequency of the primary study endpoint, induction of remission on day 28 , was not significantly different between rhuIL-10-treated patients and the placebo group. Application of rhuIL-10 for 28 days induced a marginal effect in reducing disease activity. However, the results suggest that daily doses between 4 and 8 $\mu \mathrm{g} / \mathrm{kg}$ should be further explored in future trials. The most effective dose of rhuIL-10 was $8 \mu \mathrm{g} / \mathrm{kg}$ with $46 \%$ of patients experiencing clinical improvement vs. $27 \%$ in the placebo group in the post hoc analysis. The different dose groups included about 60 patients each. In a scenario with 2 or more ineffective dose levels, the trial may have been very vulnerable to a type 2 error (which was calculated at $10 \%$ for a $30 \%$ difference between active treatment and placebo), thereby failing to detect drug activity. A large trial of the $4-$ and $8-\mu \mathrm{g} / \mathrm{kg}$ dose groups against placebo would be ideal.

There are a number of indications for an anti-inflammatory activity of IL-10 in this trial, although clinical efficacy could not be shown. These include the presence of similar dose-response characteristics for different clinical and endoscopic parameters. Patients who responded to treatment with rhuIL-10 with remission or clinical improvement had a reduction in endoscopic activity, which also favored the $8-\mu \mathrm{g} / \mathrm{kg}$ dose. Previous studies have shown a therapeutic activity of rhuIL-10 in uncomplicated $\mathrm{CD}^{21}$ and active rheumatoid arthritis. ${ }^{12}$ Further investigation of the role of endogenous IL-10 in the pathophysiology of acute and chronic inflammation may help to explain these clinical findings. Despite its rather short serum half-life (1.5-3 hours), IL-10 may be capable of inducing a prolonged biologic response in some patients. Long-term disease-modifying effects have already been observed in some patients in previous trials in $\mathrm{CD}^{21}$ as well as in rheumatoid arthritis. ${ }^{12}$ These findings raise the question of whether some individuals are particularly responsive to treatment with rhuIL-10.

Response to rhuIL-10 could represent a subgroup phenomenon, as probably seen to a lesser extent with other immune active therapeutics, including the cA2 (infliximab) monoclonal antibody against tumor necrosis factor $\alpha .^{23,37}$ Because inflammatory bowel disease is a polygenic disorder, ${ }^{38,39}$ it can be assumed that the inflammatory pathophysiology will reflect the heterogeneous cause. Therefore, closely targeted therapeutic immune interventions, which inhibit only single steps in immune cascades, may only be applicable to subgroups. The identification of immunologic and genetic molecular markers to prospectively define responder and nonresponder populations will be an important task in the development of new biologic therapies.

The bell-shaped dose-response curve seen in different activity-related parameters in this trial concurs with similar dose-response curves in uncomplicated $\mathrm{CD}^{21}$ and rheumatoid arthritis. ${ }^{14}$ In vitro immunologic studies have shown evidence for a strong anti-inflammatory effect of IL-10, which induced down-regulation of tumor necrosis factor $\alpha$ and other proinflammatory mediators. ${ }^{9}, 10,15,16,40$ However, higher concentrations of IL-10 appear to induce the expression of T-helper cell proinflammatory cytokines. ${ }^{41}$ This immunologic effect may explain why higher concentrations of IL-10 are less effective.

Both rhuIL-10 and placebo appeared to be more effective in inducing clinical improvement in patients with 
more active disease by using the median CDAI to divide the population. A subgroup effect in favor of rhuIL-10 but not of placebo in more active patients is suggested by a series of other activity-related parameters (e.g., C-reactive protein, white blood cell count). However, the formal statistical analysis failed to prove an interaction between disease activity and drug response. Therefore, future trials (i.e., with fewer dose groups and thus larger patient numbers per dose group, and a stratification for CDAI) would be needed to prove the hypothesis that a higher disease activity is a predictor of a response to rhuIL-10. The increased placebo response in the patients with a high CDAI cannot be explained on the basis of a pathophysiologic hypothesis, but certainly warrants further attention in the analysis of the placebo groups in future trials in patients with chronic active $C D$.

An increased activation of NF- $\mathrm{KB}$ appears to be a pivotal element in the immunopathophysiology of $\mathrm{CD} .{ }^{16}$ The main action of steroids appears to be induction of I $\kappa \mathrm{B},{ }^{18,19}$ whereas IL-10 strongly inhibits both IкB kinase and DNA binding of activated NF- $\mathrm{BB} \cdot{ }^{15,16,42}$ As part of the endoscopic substudy, the activation status of the $\mathrm{NF}-\kappa \mathrm{B}$ system in intestinal tissue was investigated. Patients who responded to treatment showed both induc-

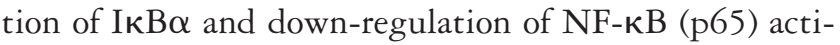
vation in comparison with nonresponders. A hypothesis derived from these data would be that IL-10, in contrast to uncomplicated Crohn's disease, ${ }^{21}$ is not capable of inducing remission in steroid-refractory patients because glucocorticoids and IL-10 have similar anti-inflammatory effects on the NF- $\mathrm{KB}$ system. Based on this hypothesis, it would be unlikely that IL-10 can induce a strong additive therapeutic effect to steroids. Further studies are needed to address the molecular mechanisms that regulate the response of the NF- $\mathrm{BB}$ system to IL- 10 .

This study shows a marginal and nonsignificant clinical effect of rhuIL-10 in inducing remission in patients with chronic, active, and steroid-refractory $\mathrm{CD}$. Clinical selection of subgroups in future prospective trials may offer a possibility to define responders and also to dissect the complex pathophysiology of $\mathrm{CD}$. Inhibition of the NF- $\kappa \mathrm{B}$ system by IL-10 is related to a clinical response. Future studies are needed to identify the molecular makeup and mechanisms of IL-10 responders and will contribute to our understanding of disease pathophysiology and cause.

\section{References}

1. Mahida YR, Wu K, Jewell DP. Enhanced production of interleukin $1-\beta$ by mononuclear cells isolated from mucosa with active ulcerative colitis or Crohn's disease. Gut 1989;30:835-838.

2. MacDonald TT, Hutchings P, Choy MY, Murch S, Cooke A. Tumour necrosis factor-alpha and interferon-gamma production mea- sured at the single cell level in normal and inflamed human intestine. Clin Exp Immunol 1990;81:301-305.

3. Stevens C, Walz G, Singaram C, Lipman ML, Zanker B, Muggia A, Antonioli D, Peppercorn MA, Strom TB. Tumor necrosis factor- $\alpha$, interleukin-1 $\beta$ and interleukin 6 expression in inflammatory bowel disease. Dig Dis Sci 1992;37:818-826.

4. Isaacs KL, Sartor RB, Haeskil JS. Cytokine mRNA profiles in inflammatory bowel disease mucosa detected by PCR amplification. Gastroenterology 1992;103:1587-1595.

5. Reinecker H-C, Steffen M, Witthoeft T, Pflueger I, Schreiber S, MacDermott RP, Raedler A. Enhanced secretion of tumor necrosis factor-alpha, IL-6, and IL-1 beta by isolated lamina propria mononuclear cells from patients with ulcerative colitis and Crohn's disease. Clin Exp Immunol 1993;94:174-181.

6. Summers RW, Switz DM, Sessions JT Jr, Becktel JM, Best WR, Kern J Jr, Singleton JW: National cooperative Crohn's disease study: results of drug treatment. Gastroenterology 1979;77: 847-869.

7. Malchow H, Ewe K, Brandes JW, Goebell H, Ehms H, Sommer $\mathrm{H}$, Jesdinsky H. European cooperative Crohn's disease study (ECCDS): results of drug treatment. Gastroenterology 1984; 86:249-266

8. GETAID, by Mary JY, Modigliani R. Development and validation of an endoscopic index of the severity for Crohn's disease: a prospective, multicentre study. Gut 1989;30:983-989.

9. de Waal Malefyt R, Yssel H, Roncarolo M-G, Spits H, de Vries JE. Interleukin 10. Curr Opin Immunol 1992;4:314-322.

10. Fiorentino DF, Bond MW, Mosmann TR. Two types of mouse T helper cells. IV. Th2 clones secrete a factor that inhibits cytokine production by Th1 clones. J Exp Med 1989;170:2081-2095.

11. Pajkrt D, Camoglio L, Tiel-van Buul MC, de Bruin K, Cutler DL, Affrime MB, Rikken G, van der Poll T, ten Cate JW, van Deventer SJ. Attenuation of proinflammatory response by recombinant human IL-10 in human endotoxemia: effect of timing of recombinant human IL-10 administration. J Immunol 1997;158:3971-3977.

12. Schreiber S, Heinig T, Thiele HG, Raedler A. Immunoregulatory role of interleukin 10 in patients with inflammatory bowel disease. Gastroenterology 1995:108:1434-1444.

13. Asadullah K, Sterry W, Stephanek K, Jasulaitis D, Leupold M, Audring H, Volk HD, Docke WD. IL-10 is a key cytokine in psoriasis. Proof of principle by IL-10 therapy: a new therapeutic approach. J Clin Invest 1998;101:783-794.

14. Keystone E, Wherry J, Grint P. IL-10 as a therapeutic strategy in the treatment of rheumatoid arthritis. Rheum Dis Clin North Am 1998;24:629-639.

15. Wang $P$, Wu P, Siegel MI, Egan RW, Billah MM. Interleukin (IL)-10 inhibits nuclear factor kappa B (NF kappa B) activation in human monocytes. IL-10 and IL-4 suppress cytokine synthesis by different mechanisms. J Biol Chem 1995;270:9558-9563.

16. Schreiber S, Nikolaus S, Hampe J. Activation of nuclear factor kappa B in inflammatory bowel disease. Gut 1998;42:477-485.

17. Baldwin AS. The NF-KB and I-KB proteins: new discoveries and insights. Annu Rev Immunol 1996;14:649-681.

18. Scheinman RI, Cogswell PC, Lofquist AK, Baldwin AS Jr. Role of transcriptional activation by $\mathrm{lkB}$ in mediation of immunosuppression by glucocorticoids. Science 1995;270:283-286.

19. Auphan N, DiDonato JA, Rosette C, Helmberg A, Karin M. Immunosuppression by glucocorticoids: inhibition of NFkB activity through induction of IkB synthesis. Science 1995;270:286290.

20. Kühn R, Löhler J, Rennick D, Rajewsky K, Müller W. Interleukin10-deficient mice develop chronic enterocolitis. Cell 1993;75: 263-274.

21. Fedorak RN, Gangl A, Elson CO, Rutgeerts P, Schreiber S, Wild G, Hanauer SB, Kilian A, Cohard M, LeBeaut A, Feagan B, for the International Interleukin 10 Inflammatory Bowel Disease Cooperative Study Group. Recombinant human interleukin 10 in the 
treatment of patients with mild to moderately active Crohn's disease. Gastroenterology 2000;119:1473-1482.

22. van Deventer SJ, Elson CO, Fedorak RN. Multiple doses of intravenous interleukin 10 in patients with inflammatory bowel disease. Gastroenterology 1997;1113:383-389.

23. Targan SR, Hanauer SB, van Deventer SJH, Mayer L, Present DH, Braakman T, de Woody KL, Schaible TF, Rutgeerts PJ. A shortterm study of chimeric monoclonal antibody CA2 to tumor necrosis factor $\alpha$ for Crohn's disease. N Engl J Med 1997;337:10291035.

24. Best WR, Becktel JM, Singleton JW, Kern F Jr. Development of a Crohn's disease activity index. National Cooperative Crohn's Disease Study. Gastroenterology 1976;70:439-444.

25. Hou J, Schindler U, Henzel WJ, Ho TC, Brasseur M, McKnight SL. An interleukin-4-induced transcription factor: IL-4 stat. Science 1994;265:1701-1706.

26. Osborn L, Kunkel S, Nabel GJ. Tumor necrosis factor and interleukin 1 stimulate the human immunodeficiency virus enhancer by activation of the nuclear factor kb. Proc Natl Acad Sci U S A 1989;86:2335-2340.

27. Nikolaus S, Raedler A, Stikas N, Kühbacher T, Fölsch UR, Schreiber S. Mechanisms in failure of infliximab in Crohn's disease. Lancet 2000;356:1475-1479.

28. Scholtz B, Lamb K, Rosfjord E, Kingsley M, Rizzino A. Appearance of nuclear protease after embryonal carcicomal cells undergo differentiation. Dev Biol 1996;173:420-427.

29. Dent CL, Latchman DS. The overlapping octamer/TAATGARAT motif is a high-affinity binding site for the cellular transcription factors Oct-1 and Oct-2. Biochem J 1991;277:541-545.

30. Henell F, Glaumann H. Effect of leupeptin on the autophagic vacuolar system of rat hepatocytes. Correlation between ultrastructure and degradation of membrane and cytosolic proteins. Lab Invest 1984;51:46-56.

31. Lowry $\mathrm{OH}$, Rosebrough NJ, Farr AL, Randall RJ. Protein measurements with the Folin phenol reagent. J Biol Chem 1951;193: 265-275.

32. Sachs L. Angewandte Statistik. 7th ed. Heidelberg: Springer, 1992.

33. Wilcoxon F. Some rapid approximate statistical procedures. Stanford, CT: American Cyanamid Co., 1949.

34. Ware JE Jr, Sherbourne CD. The MOS 36-item short-form health survey (SF-36). I. Conceptual framework and item selection. Med Care 1992;30:473-483.

35. Guyatt G, Mitchell A, Irvine EJ, Singer J, Williams N, Goodacre R, Tompkins C. A new measure of health status for clinical trials in inflammatory bowel disease. Gastroenterology 1989;96:804810.

36. McHorney CA, Ware JE Jr, Raczek AE. The MOS 36-Item ShortForm Health Survey (SF-36): II. Psychometric and clinical tests of validity in measuring physical and mental health constructs. Med Care 1993;31:247-263.
37. Stack WA, Mann SD, Roy AJ, Heath P, Sopwith M, Freeman J, Holmes G, Long R, Forbes A, Kamm MA. Randomised controlled trial of CDP571 antibody to tumour necrosis factor-alpha in Crohn's disease. Lancet 1997;349:521-524.

38. Hugot $P$, Thomas $G$. Genetics of inflammatory bowel disease. Int J Colorect Dis 1999;14:2-9.

39. Schreiber S, Hampe J. Genetics and inflammatory bowel disease. Curr Opin Gastroenterol 1999;15:315-321.

40 Stordeur P, Goldman M. Interleukin-10 as a regulatory cytokine induced by cellular stress: molecular aspects. Int Rev Immunol 1998;16:501-522.

41. van Montfrans $C$, van de Ende A, Fedorak RN, Gangl A, Elson CO, Rutgeerts P, Schreiber S, Wild G, Hanauer S, Grint P, van Deventer SJH. Anti- and pro-inflammatory effects of interleukin-10 in mild to moderate Crohn's disease (abstr). Gastroenterology 1999;116:A3370.

42. Schottelius AJG, Mayot MW, Sartor RB, Baldwin AS. Interleukin-10 signaling blocks inhibitor of $\kappa B$ kinase activity and nuclear factor кB DNA binding. J Biol Chem 1999;274:31868-31874.

Received September 15, 1999. Accepted June 28, 2000.

Address requests for reprints to: Stefan Schreiber, M.D., First Medical Department, Christian-Albrechts-University, Schittenhelmstrasse 12, 24105 Kiel, Germany. e-mail: s.schreiber@mucosa.de; fax: (49) 431-597-1302.

Part of this work was presented at the 99th meeting of the American Gastroenterological Association in New Orleans, Louisiana (May 15-19, 1998).

Supported by a grant from Schering-Plough Research Institute (Kenilworth, NJ). The fellowship of Dr. Nikolaus and the laboratory work were supported by additional grants from Mucosa immunologie gemeinnützige Forschungsgesellschaft $\mathrm{mbH}$ (MFG), a training and mobility of researchers program of the European Commission (ERB4061-PL-97-0389), and by DFG SFB 415.

The authors thank Ulrich Meinzer for contribution in the preparation of samples, conduction of in vitro experiments, and handling of experimental data for the NF-kB work.

The Interleukin 10 Inflammatory Bowel Disease Cooperative Study Group consists of the following centers. The number of patients enrolled at each center is given in parentheses: S. Schreiber (27), R. N. Fedorak (25), 0. H. Nielsen (20), G. Wild (18), N. C. Williams (17), M. Jacyna (12), B. A. Lashner (11), P. Rutgeerts (10), A. Gangl (10), K. Isaacs (10), M. Gregor (9), E. J. Bernard (9), J. C. Koningsberger (8), C. Bernstein (8), A. H. Steinhart (8), C. Elson (7), S. Targan (7), S. J. H. van Deventer (7), J. Irvine (7), L. R. Da Costa (7), B. Feagan (7), S. Hanauer (6), L. F. Mayer (6), S. Katz (6), R. Befrits (6), J. Schölmerich (6), L. Abreu (6), M. A. Bigard (6), C. Sninsky (5), H. Tilg (5), P. Pare (5), W. J. Tremaine (4), B. Sands (4), B. Duclos (4), S. Chaussade (4), D. Levine (3), S. P. Riepe (3), R. A. van Hogezand (3), A. Ferguson (2), and B. D. Greenwald (1). 